\title{
Práticas assistenciais das Equipes de Saúde da Família em quatro grandes centros urbanos
}

\author{
Healthcare practices of Family Health Teams in four major cities
}

\author{
Adriano M aia dos Santos ${ }^{1}$ \\ LigiaGiovanella² \\ $M$ aria $H$ elena $M$ agalhães de $M$ endonça ${ }^{2}$ \\ Carla Lourenço Tavares de Andrade ${ }^{2}$ \\ $M$ aria I nês Carsalade $M$ artins ${ }^{2}$ \\ M arcela Silva da Cunha ${ }^{2}$
}

${ }^{1}$ Instituto M ultidisciplinar em Saúde, Campus Anísio Teixeira, Universidade Federal da Bahia. Rua Rio de Contas 58/Quadra 17/Lote 58, Candeias. 45055-090 Vitória da Conquista BA. maiaufba@ufba.br

${ }^{2}$ Escola Nacional deSaúde Pública Sergio Arouca,

Fundação O swaldo Cruz
Abstract This paper examines reports on how care is administered by Family Health Teams (FHT) doctors and nurses in four state capitals. It identifies issues relating to priority actions, routine activities and the association between the professional profileand how selected activitiesare performed, in an attempt to ascertain how far these approximate to the comprehensive approach to primary health care. The cross-section reflects results from data collected via self-applied questionnaires. Cross-analyses were made using the Pearson chi-square $\left(\div^{2}\right)$ test for categorical variables. A and B variables are, or are not, associated, at a $5 \%$ level of significance. The analyses point to a tendency to strike a balancein meeting programmed and spontaneous demand, corroborating the person-centered approach. Action to address chronic infectious disorders is not a priority for all FHTs, which impairs health surveillance actions and comprehensive care. Home visits are not yet a weekly activity for all personnel. Lack of involvement in community activities restricts care to conventional practices and undermines the logic of change of model. Contradictions identified between training and practice indicate a need to review policies for ongoing professional development.

Key words Primary healthcare, Family health program, $\mathrm{H}$ ealth evaluation, $\mathrm{H}$ ealth professional, Human resource training
Resumo 0 artigo analisa as práticas assistenciais dos médicos e enfermeiros de Equipes de Saúde da Família (EqSF) em quatro capitaisa partir deinquéritos. I dentifica aspectos relacionados às ações prioritárias, atividades rotineiras e a associação entreo perfil profissional ea realização deatividades selecionadas, buscando evidenciar o quanto se aproximam de práticas integrais. 0 recorte referesea resultados com dados coletados por questionários autoaplicados. 0 teste usado na análise dos cruzamentos foi o qui-quadrado de Pearson $\left(\chi^{2}\right)$ para variáveis categóricas. As variáveis $A$ e $B$ são associadas ou não, ao nível de significância de $5 \%$. As análises indicam tendência a um balanço entre atendimento à demanda programada e espontânea, corroborando práticas centradas nas pessoas. Ações a agravos infecciosos de curso longo não são prioridades para todas as EqSF, comprometendo as ações de vigilância à saúde e as práticas integrais. A aten ção domiciliar, ainda, não éuma prática semanal para todos os profissionais. Insuficiente envolvimento com atividades na comunidade restringe a produção do cuidado às práticas convencionais e comprometem a lógica de mudança de modelo. Contradições identificadas entre formação e práticas sugerem necessidade de rever as políticas de educação permanente.

Palavras-chave Atenção Primária à Saúde, Programa Saúdeda Família, Avaliação em saúde, Profissional de saúde, Formação de recursos humanos 


\section{Introdução}

A Estratégia Saúde da Família (ESF) tem cumprido parcial mentesua agenda ${ }^{1}$, nesse sentido sua intensa capilarização impõe desafios aos formuladores de políticas, provocando debates em relação à resolubilidade, ao processo de trabalho e às práticas assistenciais², coordenação dos cuidados, posição e integração à rede de serviços ${ }^{3}$, gestão do trabal ho ${ }^{4}$ ea intersetorialidade 5 . As experiências em curso revelam grande diversidade dos modelos assistenciais vis-à-vis, imensas disparidades inter e intrarregionais e desigual dades da sociedade brasileira ${ }^{6}$.

A ESF é capaz de provocar mudanças nas práticas, com superioridade em comparação aos modelos tradicionais, impactando na saúde da populaçãa ${ }^{7,8}$, nessa perspectiva, a Política Nacional de Atenção Básica (PNAB) ${ }^{9}$ descreve genericamente características comuns eatribuições específicas de cada trabalhador das Equipes deSaúde da Família (EqSF) para orientação de práticas assistenciais integrais. Campos et al. ${ }^{10}$, por sua vez, sintetizam diretrizes para que a ESF cumpra esse papel: acolhimento à demanda ebusca ativa com avaliação de vulnerabilidade (visita domiciliar e análise do território adscrito); clínica ampliada e compartilhada com usuários (dimensão biológica, subjetiva esocial); saúde coletiva (prevenção e promoção no território) e participação social (inserção da equipe na comunidade e organização dos serviços com usuários).

Práticas assistenciais compreendem um conjunto de atividades prioritárias e rotineiras, em nível microssocial, realizadas no processo de trabalhos das EqSF, que atendem aos atributos específicos àAtenção Primária à Saúde - APS (portadeentrada preferencial, Iongitudinalidade, elenco de serviços, coordenação, enfoque familiar e orientação para comunidade) ${ }^{11,12}$. A robustez nas práticas assistenciais sinaliza o quanto elas ampliam o escopo do cuidado, na perspectiva de práticas integrais, ou seja, o quanto as ações das EqSF dão conta de acolher a demanda organizada, permanecendo aberta a demanda espontânea, produzindo atividades clínicas direcionadas às pessoas em diferentes fases da vida e com distintas necessidades desaúde, comportan do ações individuais e coletivas, não restritas à unidade de saúde da família (USF), compartilhando o cuidado entre os diferentes membros da equipe, além de envolver-se com questões de planejamento, gestão e educação permanente.

Assim, as práticas assistenciais integrais são dispositivos para a consolidação de uma APS abrangente, pois organizam serviços pautados na produção do cuidado, modelando a micropolítica do trabalho em saúde. 0 cuidado em saúde se realiza no momento do encontro entre trabalhador-usuário, logo "as relações interpessoais é que são importantes, com predomínio dos atributos relacionados ao acesso, à comunicação, à informação eà efetividade da atenção"13.

Tais argumentos coadunam com a "imagemobjetivo" das práticas assistenciais esperadas e do funcionamento ideal das EqSF, visto que uma boa organização dos serviços de APS contribui para melhoria da atenção, acarretando efeitos positivos à saúde da população e à eficiência do sistema ${ }^{14}$.

N esta perspectiva, o presente estudo analisa a organização das práticas assistenciais nas EqSF em quatro centros urbanos, identificando aspectos relacionados às ações prioritárias, atividades rotineiras e a associação entre o perfil profissional e a realização de determinadas atividades, buscando evidenciar o quanto se aproximam de práticas integrais.

\section{Metodologia}

As práticas assistenciais são analisadas com base nos dados de pesquisa aval iativa sobre I mplementação da ESF ${ }^{3}$, com estudos de caso em Aracaju, Belo H orizonte, Florianópolis e Vitória. Os municípios foram escolhidos intencionalmente de modo a privilegiar experiências consolidadas, considerando-se: el evada cobertura populacional da ESF (>50\%), tempo de implementação mínimo de cinco anos, presença de práticas inovadoras e/ ou bem sucedidas na mudança do modelo assistencial, identificadas a partir de entrevistas com dirigentes do M inistério da Saúde (MS).

0 recorte selecionado para o presente artigo refere-se a resultados de inquéritos com dados coletados por meio de questionários autoaplicados a médicos e enfermeiros, com trabalho de campo realizado de maio a setembro de 2008. A seleção da amostra de profissionais de saúde foi feita com base nos registros administrativos do Cadastro Nacional de Estabelecimentos de Saúde disponibilizados pelo DAB. Em Florianópolis e Vitória, realizou-se um censo, correspondendo, respectivamente, a 79 e $53 \mathrm{EqSF}$, enquanto selecionou-se, com equiprobabilidade, 80 das 127 EqSF de Aracaju e 90 das 469 EqSF de Belo H orizonte, identificando-se, para cada equipe, médico e enfermeiro. Os pesos amostrais foram calculados pelo inverso das probabilidades de in- 
clusão na amostra. Aplicou-se um total de 483 questionários: Aracaju - 67 enfermeiros e 55 médicos; Belo Horizonte - 75 enfermeiros e 72 médicos; Florianópolis - 70 enfermeiros e 61 médicos; Vitória - 46 enfermeiros e 37 médicos. Em Aracaju, ocorreram 38 perdas entre médicos e enfermeiros das EqSF. Em Belo Horizonte houve 33 perdas, em Florianópolis, 27 e em Vitória, 21. As perdas foram ocasionadas por diversos motivos: férias, licença prêmio, doença ou maternidade, não devolução do questionário, recusa ou não existência do profissional na EqSF.

Todos os dados primários resultantes dos estudos transversais foram codificados e computados no programa CSPRO versão 3.3 e distribuídos em frequências simples por município, tipo de informante e variável.

As práticas assistenciais focalizaram o âmbito da atuação profissional e a organização do trabalho, abordando-se dois aspectos: a) Ações prioritárias; b) Atividades rotineiras. Os resultados são analisados e apresentados por cidade.

As ações prioritárias listadas no instrumento de pesquisa correspondem ao conjunto de atividades que devem ser desenvolvidas pelos profissionais demaneira programática. Contemplaramse, na pesquisa, ciclos de vida (crianças, adolescentes e idosos), saúde da mulher (planejamento familiar, pré natal, puerpério e controle do câncer do colo uterino), controle a agravos crônicodegenerativos e ações a agravos infecciosos, perguntando-se aos profissionais se eram consideradas como ações prioritárias por sua equipe.

As atividades rotineiras compõem o elenco de ações produzidas no processo de trabalho das EqSF, e para fim de análise foram distribuídas em cinco grupos: (a) Ações individuais na USF, (b) Ações de educação em saúde, (c) Atividades em grupo e comunitárias, (d) Visita domiciliar, (e) Atividades de capacitação e gerenciais. Solicitouse que profissionais das equipes indicassem atividades rotineiramente realizadas e sua frequência, com baseem experiência dosúltimos trinta dias a partir de uma lista de atividades e frequência de realização apresentada no questionário.

$\mathrm{N}$ a categoria educação em saúde, o escopo de ações incluído dependeu da concepção individual de cada respondente, ou seja, do reconhecimento do profissional da realização rotineira, ou não, destetipo deatividade. As atividades degrupo com usuários na USF demarcam o espaço de grupos populacionais específicos para ações programáticas de caráter terapêutico e educativo. As reuniões com a comunidade correspondem a ações direcionadas a temas mais genéricos sobre problemas no território, categoria usada como proxy para a ação comunitária e intersetorial e incentivo à participação social pelas EqSF, como preconizado.

Tomando-se o conjunto dos médicos e enfermeiros, foram analisadas associações entre perfil profissional e atividades realizadas, isto é, entre as seguintes características: a) formação em Saúde da Família ou em M edicina de Família e Comunidade; b) tempo de atuação na ESF (até 48 meses e acima); e a realização das seguintes atividades características da EqSF: a) grupos com usuários; b) reunião na comunidade; e, c) visita domiciliar. 0 teste usado na análise dos cruzamentos foi o qui-quadrado de Pearson $\left(\chi^{2}\right)$ para variáveis categóricas. As variáveis A eB são associadas ou não, ao nível de significância de $5 \%$.

$\mathrm{O}$ projeto de pesquisa foi aprovado pelo Comitê de Ética em Pesquisa da Escola Nacional de Saúde Pública da Fiocruz efinanciado pelo DAB/ SAS/MS.

Resultados

\section{Ações prioritárias}

$N$ as quatro cidades, quase a unanimidade ( $>$ 91\%) dos médicos e enfermei ros apontaram que as equipes estabelecem prioridades no atendimento à população cadastrada (em Vitória, 100\%). Entretanto, as prioridades eleitas variam por tipo de profissional e nas diferentes cidades, conforme apresentado na Tabela 1.

Em relação aos ciclos de vida, a atenção à saúde da criança apresenta-se como programação maishabitual com percentagenssuperiores a $76 \%$, sendo que Vitória se destaca com $97 \%$, segundo médicos, e 94\%, para enfermeiros. Ações dirigidas ao grupo de adolescentes mostram menores proporções entre as demais ações prioritárias, apresentando máximo entre os enfermeiros de Vitória (45\%) e incipiente entre médicos de Belo Horizonte ( $10 \%)$. Por sua vez, a priorização da saúde dos idosos exibe proporções de 71\% e 75\% em Aracaju, $68 \%$ e $59 \%$ em Belo H orizonte, $70 \%$ e 76\% em Florianópolis, sendo prioridade para uma menor proporção de profissionais em Vitória com $67 \%$ e $53 \%$, respectivamente, no julgamento de médicos e enfermeiros.

Atividades concernentes à saúde da mulher têm no pré-natal a ação prioritária mais comum, referida por ambos os profissionais, nas quatro cidades, numa proporção maior que $83 \%$, sendo prioridade para praticamentetodos os enfermei- 
Tabela 1. Ações prioritárias das equipes de Saúde da Família informadas por médicos e enfermeiros (\%), em quatro grandes centros urbanos, 2008.

\begin{tabular}{|c|c|c|c|c|c|c|c|c|}
\hline \multirow{3}{*}{ Ações prioritárias } & \multicolumn{4}{|c|}{ Aracaju } & \multicolumn{4}{|c|}{ Belo Horizonte } \\
\hline & \multicolumn{2}{|c|}{ Médico } & \multicolumn{2}{|c|}{ Enfermeiro } & \multicolumn{2}{|c|}{ M édico } & \multicolumn{2}{|c|}{ Enfermeiro } \\
\hline & $\mathrm{n}$ & $\%$ & $\mathrm{n}$ & $\%$ & $\mathrm{n}$ & $\%$ & $\mathrm{n}$ & $\%$ \\
\hline \multicolumn{5}{|l|}{ Ciclos de vida } & 68 & 94,4 & 73 & 97,3 \\
\hline Atenção à criança & 42 & 76,4 & 57 & 85,1 & 61 & 84,7 & 69 & 92,0 \\
\hline Atenção ao adolescente & 11 & 20,0 & 29 & 43,6 & 7 & 9,7 & 14 & 18,7 \\
\hline Atenção aos idosos & 39 & 70,9 & 50 & 74,6 & 49 & 68,1 & 44 & 58,7 \\
\hline \multicolumn{9}{|l|}{ Saúde da mulher } \\
\hline Planejamento familiar & 38 & 69,0 & 61 & 91,0 & 42 & 58,3 & 54 & 72,0 \\
\hline Atenção pré-natal & 46 & 83,6 & 65 & 97,0 & 64 & 88,9 & 71 & 94,7 \\
\hline Atenção ao puerpério & 23 & 41,8 & 55 & 82,1 & 35 & 48,6 & 54 & 72,0 \\
\hline \multirow{2}{*}{\multicolumn{9}{|c|}{ Agravos crônico-degenerativos }} \\
\hline & & & & & & & & \\
\hline Controle de diabetes & 48 & 87,3 & 64 & 95,5 & 63 & 87,5 & 67 & 89,3 \\
\hline Controle de hipertensão & 48 & 87,3 & 63 & 94,0 & 66 & 91,7 & 68 & 90,7 \\
\hline \multicolumn{9}{|l|}{ Agravos infecciosos } \\
\hline Controle de dengue & 32 & 58,0 & 56 & 83,6 & 34 & 47,2 & 43 & 56,9 \\
\hline Controle de hanseníase & 40 & 72,7 & 60 & 89,6 & 14 & 19,4 & 22 & 29,3 \\
\hline Controle de tuberculose & 39 & 70,9 & 60 & 89,6 & 37 & 51,4 & 46 & 61,3 \\
\hline Controle de DST/AIDS & 21 & 38,2 & 48 & 71,6 & 12 & 16,7 & 17 & 22,7 \\
\hline \multirow{3}{*}{ Ações prioritárias } & \multicolumn{4}{|c|}{ Florianópolis } & \multicolumn{4}{|c|}{ Vitória } \\
\hline & \multicolumn{2}{|c|}{ M édico } & \multicolumn{2}{|c|}{ Enfermeiro } & \multicolumn{2}{|c|}{ Médico } & \multicolumn{2}{|c|}{ Enfermeiro } \\
\hline & $\mathrm{n}$ & $\%$ & $\mathrm{n}$ & $\%$ & $\mathrm{n}$ & $\%$ & $\mathrm{n}$ & $\%$ \\
\hline $\begin{array}{l}\text { ESF estabelece prioridades } \\
\text { Ciclos de vida }\end{array}$ & 57 & 93,1 & 64 & 91,3 & 37 & 100,0 & 46 & 100,0 \\
\hline Atenção à criança & 49 & 80,3 & 61 & 87,1 & 36 & 97,4 & 43 & 93,9 \\
\hline Atenção ao adolescente & 7 & 11,5 & 9 & 20,0 & 11 & 30,8 & 21 & 44,9 \\
\hline Atenção aos idosos & 43 & 70,5 & 53 & 75,7 & 25 & 66,7 & 24 & 53,1 \\
\hline \multicolumn{9}{|l|}{ Saúde da mulher } \\
\hline Planejamento familiar & 25 & 41,0 & 46 & 65,7 & 31 & 84,6 & 37 & 79,6 \\
\hline Atenção pré-natal & 53 & 86,9 & 61 & 87,1 & 36 & 97,4 & 45 & 98,0 \\
\hline Atenção ao puerpério & 39 & 63,9 & 54 & 77,1 & 25 & 66,7 & 38 & 81,6 \\
\hline Controle de câncer do colo uterino & 32 & 52,4 & 51 & 72,8 & 33 & 89,7 & 39 & 85,7 \\
\hline \multicolumn{9}{|l|}{ Agravos crônico-degenerativos } \\
\hline Controle de diabetes & 43 & 70,5 & 55 & 78,6 & 36 & 97,4 & 45 & 98,0 \\
\hline Controle de hipertensão & 43 & 70,5 & 55 & 78,6 & 37 & 100,0 & 46 & 100,0 \\
\hline \multicolumn{9}{|l|}{ Agravos infecciosos } \\
\hline Controle de dengue & 5 & 8,0 & 18 & 25,7 & 18 & 48,7 & 28 & 61,2 \\
\hline Controle de hanseníase & 11 & 18,0 & 20 & 28,6 & 16 & 43,6 & 30 & 65,3 \\
\hline Controle de tuberculose & 33 & 54,1 & 43 & 61,4 & 17 & 46,2 & 32 & 69,4 \\
\hline Controle de DST/AIDS & 16 & 26,2 & 27 & 38,6 & 15 & 41,0 & 25 & 55,1 \\
\hline
\end{tabular}

Fonte: $\mathrm{N}$ upes/Daps/Ensp/Fiocruz. Pesquisa Saúde da Família, quatro estudos decaso, 2008. N ota: A racaju: $n=55$ médicos en $=67$ enfermeiros; Belo Horizonte: $n=72$ médicos en $=75$ enfermeiros; Florianópolis: $n=61$ médicos en $=70$ enfermeiros; Vitória: $n=37$ médicos en $=46$ enfermeiros

ros deAracaju emédicos/enfermeiros deVitória. Planejamento familiar é prioridade principalmente para enfermeiros, destacando-se enfermeiros em Aracaju (91\%) e a baixa priorização por médicos em Florianópolis (41\%). Cuidados à mulher no período pós-parto e controle de cân- cer de colo uterino são também ações de maior prioridade para enfermeiros, com destaque para Aracaju ( $82 \%$ e $91 \%$ ) e Vitória ( $81 \%$ e $86 \%$ ).

$\mathrm{Na}$ visão dos profissionais, o controle aos agravos crônico-degenerativos (diabetes ehipertensão) éuma ação definida como prioritária em 
altas porcentagens. Controle da hipertensão é a ação prioritária para grande proporção de médicos e enfermeiros, chegando a ser citada por todos em Vitória (100\%). Diabetes éum agravo crônico acompanhado demaneira prioritária pela equipe nas quatro cidades, sendo apontado por 98\% dos médicos e enfermeiros de $V$ itória.

Ações prioritárias a agravos infecciosos distribuem-se no controle da dengue, hanseníase, tuberculose e DST/AIDS, com resultados mais díspares entre as cidades e em todas com maior importância para enfermeiros. Cerca de metade dos profissionais de Aracaju, Belo Horizonte e Vitória estabelecem prioridade para controle da dengue, destoando enfermeiros de Aracaju (83\%). Contudo, é uma ação não priorizada em Florianópolis ( $8 \%$ e 26\%). Controle da hanseníase etuberculose é priorizado pela grande maioria dos profissionais ( $>70 \%$ ) somente em Aracaju. Nas demais capitais investigadas, controle detuberculosefoi apontado por cerca da metade dosmédicos, 69\% dos enfermeiros, em Vitória, e três quintos dos enfermeiros, em Belo H orizonte eFlorianópolis. Controle de hanseníase, por sua vez, é citado somente por um quinto dos médicos e menos de $30 \%$ dos enfermeiros de Belo Horizonte e Florianópolis.

A atividade de DST/Aids apresentou-se com prioridade elevada apenas para enfermeiros de Aracaju (72\%) e bastante baixa de acordo com médicos e enfermeiros de Belo H orizonte (17\% e $23 \%$ ).

\section{Atividades rotineiras}

As atividades rotineiras que compõem o elenco de ações produzidas no processo de trabalho dos médicos e enfermeiros das EqSF são apresentadas nas Tabelas 2 e 3.

Entre as atividades rotineiras pesquisadas, as ações individuais naUSF são maisfrequentemente realizadas sejam aquelas programáticas direcionadas aos grupos prioritários sejam aquelas de atendimento à demanda espontânea. Atendimento à demanda espontânea é realizado diariamente em Aracaju e Belo Horizonte ( $>92 \%$ ), Florianópolis ( $>84 \%$ ), para ambos os profissionais, sendo que, em Vitória, tal atividade, decrescepara $35 \%$ dos enfermeiros e $56 \%$ dos médicos. Outra atividadecom frequência diária para médicos éa consulta individual à população cadastrada, ficando acima de $87 \%$ em todas as cidades. Asconsultas de enfermagem à população cadastrada são apontadas como diárias ou realizadas de 1 a
3 vezes por semana, nessa ordem, em Belo H orizonte $(66 \%$; $30 \%)$, Florianópolis (61\%; $34 \%)$, Vitória $(57 \% ; 39 \%)$ e, predominantemente diária, em Aracaju (93\%). Consultas individuais a grupos prioritários são realizadas por $75 \%$ ou mais dos médicos e enfermeiros uma a três vezes por semana ou todos os dias. Atendimentos de urgência são acolhidos por parte das equipes em todas as cidades principalmente por médicos, contudo em menores proporções.

Ações de educação em saúde são reconhecidas como realizadas diariamente por menos de um terço dos profissionais, ainda que mais de $86 \%$ dos enfermeiros e $75 \%$ dos médicos as realizem em algum momento. Atividades de grupo com usuários na USF são ações rotineiras de médicos e enfermeiros, com exceção de Aracaju, onde $56 \%$ dos médicos não realizam essa atividade. Reuniões com a comunidade são realizadas com baixafrequência. Somenteum terço dos médicos, em Aracaju eFlorianópolis, eum quarto deles, em Vitória eBelo H orizonte, participam ou organizam reuniões com a comunidade. Entre enfermeiros esta é uma atividade um pouco mais frequente, ainda que menos da metade cumpra essa atividade em três das cidades, com exceção de Aracaju onde $61 \%$ realizam.

Visita domiciliar éuma atividade rotineira de enfermeiros e médicos, com uma pequena proporção de profissionais que não a realiza ( $<7 \%)$, em todas as capitais investigadas. Trata-se de atividade, predominantemente semanal, com destaque para médicos (93\%), em Aracaju, e enfermeiros ( $92 \%$ e $86 \%$ ), respectivamente, em Aracaju e Vitória, que realizam essa atividade pelo menos uma vez por semana. $\mathrm{N}$ as demais cidades entre um terço e um quarto de médicos e enfermeiros não realizam, semanalmente, visitas domiciliares.

No grupo das atividades de capacitação e gerenciais, atividades de administração e gerência predominam entre enfermeiros, sendo em Florianópolis realizadas por 89\% eem Vitória por 83\%. $M$ édicos realizam poucas atividades de administração, no máximo 21\%, em Florianópolis e Vitória, ficando abaixo de $11 \%$ nas demais cidades.

Por sua vez, reuniões de equipe são comuns aos médicos ( $>82 \%$ ) eenfermeiros (>91\%) com frequência semanal ou mensal. A supervisão do trabalho dos auxiliares de enfermagem e ACS é incumbência realizada por praticamente todos enfermeiros, e começa a fazer parte, também, do processo de trabalho médico, alcançando $48 \%$ em Florianópolis. 
Tabela 2. Frequência de atividades rotineiras informada por médicos (\%) da Estratégia Saúde da Família, quatro grandes centros urbanos, 2008.

\begin{tabular}{|c|c|c|c|c|c|c|c|c|}
\hline \multirow{3}{*}{ Atividades } & \multicolumn{8}{|c|}{ Aracaju } \\
\hline & \multicolumn{2}{|c|}{$\begin{array}{l}1 \text { a } 2 \text { vezes } \\
\text { por mês }\end{array}$} & \multicolumn{2}{|c|}{$\begin{array}{l}1 \text { a } 3 \text { vezes } \\
\text { por semana }\end{array}$} & \multicolumn{2}{|c|}{$\begin{array}{l}\text { Todos } \\
\text { os dias }\end{array}$} & \multicolumn{2}{|c|}{$\begin{array}{l}\text { Não } \\
\text { realiza }\end{array}$} \\
\hline & $\mathrm{n}$ & $\%$ & $\mathrm{n}$ & $\%$ & $\mathrm{n}$ & $\%$ & $\mathrm{n}$ & $\%$ \\
\hline \multicolumn{9}{|l|}{ A ções individuais na USF } \\
\hline Atendimento à demanda espontânea & 0 & 0,0 & 3 & 5,5 & 51 & 92,7 & 1 & 1,8 \\
\hline Consulta clínica individual à população cadastrada & 0 & 0,0 & 5 & 9,1 & 48 & 87,3 & 2 & 3,6 \\
\hline Consulta clínica individual para grupos prioritários & 2 & 3,6 & 12 & 21,8 & 35 & 63,6 & & 510,9 \\
\hline Atendimento de urgência & 3 & 5,5 & 8 & 14,5 & 37 & 67,3 & & 72,7 \\
\hline Ações de educação em saúde & 18 & 32,7 & 7 & 12,7 & 16 & 29,1 & & 425,5 \\
\hline \multicolumn{9}{|l|}{ Atividades em grupo e comunitárias } \\
\hline Atividades de grupo com usuários na USF & 20 & 36,4 & 3 & 5,5 & 1 & 1,8 & \multicolumn{2}{|c|}{3156,4} \\
\hline Reunião com a comunidade & 16 & 29,1 & 4 & 7,3 & 0 & 0,0 & \multicolumn{2}{|c|}{3563,6} \\
\hline Visita domiciliar & 3 & 5,5 & 51 & 92,7 & 0 & 0,0 & 1 & 1,8 \\
\hline \multicolumn{9}{|l|}{ Atividades de capacitação e gerenciais } \\
\hline Reunião de equipe & 29 & 52,7 & 17 & 30,9 & 1 & 1,8 & \multicolumn{2}{|c|}{814,5} \\
\hline Atividades de capacitação & 34 & 61,1 & 7 & 13,0 & 0 & 0,0 & \multicolumn{2}{|c|}{1425,9} \\
\hline Reunião com a coordenação/ supervisão & 28 & 50,9 & 4 & 7,3 & 0 & 0,0 & \multicolumn{2}{|c|}{2341,8} \\
\hline Supervisão do trabalho dos auxiliares de enfermagem e ACS & 9 & 16,4 & 5 & 9,1 & 5 & 9,1 & \multicolumn{2}{|c|}{3665,5} \\
\hline \multirow[t]{2}{*}{ Atividades de administração e gerência } & 4 & 7,3 & 2 & 3,6 & 0 & 0,0 & & 989,1 \\
\hline & \multicolumn{8}{|c|}{ Belo Horizonte } \\
\hline \multirow{2}{*}{ Atividades } & \multicolumn{2}{|c|}{$\begin{array}{c}1 \text { a } 2 \text { vezes } \\
\text { por mês }\end{array}$} & \multicolumn{2}{|c|}{$\begin{array}{c}1 \text { a } 3 \text { vezes } \\
\text { por semana }\end{array}$} & \multicolumn{2}{|c|}{$\begin{array}{l}\text { Todos } \\
\text { os dias }\end{array}$} & \multicolumn{2}{|c|}{$\begin{array}{l}\text { Não } \\
\text { realiza }\end{array}$} \\
\hline & $\mathrm{n}$ & $\%$ & $\mathrm{n}$ & $\%$ & $\mathrm{n}$ & $\%$ & $\mathrm{n}$ & $\%$ \\
\hline \multicolumn{9}{|l|}{ Ações individuais na USF } \\
\hline Atendimento à demanda espontânea & 0 & 0,0 & 3 & 4,2 & 69 & 95,8 & & \\
\hline Consulta clínica individual à população cadastrada & 0 & 0,0 & 5 & 6,9 & 67 & 93,1 & & 0,0 \\
\hline Consulta clínica individual para grupos prioritários & 7 & 9,9 & 22 & 31,0 & 36 & 50,7 & & 58,5 \\
\hline Atendimento de urgência & 2 & 2,8 & 20 & 27,8 & 42 & 58,3 & & 11,1 \\
\hline A ções de educação em saúde & 25 & 34,7 & 14 & 19,4 & 16 & 22,2 & & 723,6 \\
\hline \multicolumn{9}{|l|}{ Atividades em grupo e comunitárias } \\
\hline Atividades de grupo com usuários na USF & 27 & 37,5 & 32 & 44,4 & 0 & 0,0 & & 318,1 \\
\hline Reunião com a comunidade & 13 & 18,3 & 4 & 5,6 & 1 & 1,4 & & 474,6 \\
\hline Visita domiciliar & 23 & 31,9 & 45 & 62,5 & 0 & 0,0 & & 5,6 \\
\hline \multicolumn{9}{|l|}{ Atividades de capacitação e gerenciais } \\
\hline Reunião de equipe & 16 & 22,2 & 55 & 76,4 & 0 & 0,0 & & \\
\hline Atividades de capacitação & 23 & 31,9 & 1 & 1,4 & 0 & 0,0 & & 866,7 \\
\hline Reunião com a coordenação/ supervisão & 35 & 48,6 & 10 & 13,9 & 0 & 0,0 & & 737,5 \\
\hline Supervisão do trabalho dos auxiliares de enfermagem e ACS & 3 & 4,2 & 15 & 20,8 & 13 & 18,1 & & 56,9 \\
\hline Atividades de administração e gerência & 7 & 9,7 & 1 & 1,4 & 0 & 0,0 & & 488,9 \\
\hline
\end{tabular}

Características do perfil dos profissionais e realização de atividades selecionadas

Entre médicos com menos tempo de atuação, observaram-se proporções levemente mais elevadas deprofissionaisquerealizam atividades degrupo, reuniões na comunidade evisita domiciliar. 0 mesmo ocorrendo para realização de atividades de grupo por enfermeiros. Todavia, não foi evidenciada associação significativa estatisticamente $(p<5 \%)$ entre tempo de atuação de médicos e enfermeiros e as três atividades relacionadas.

Entre médicos, a formação (ter frequentado curso deespecialização em Saúdeda Família [SF], ou ter o título de especialista em M FC [medicina defamília e comunidade]) está positivamente as- 
Tabela 2. continuação

\begin{tabular}{|c|c|c|c|c|c|c|c|}
\hline \multirow{2}{*}{ Atividades } & \multicolumn{7}{|c|}{ Florianópolis } \\
\hline & & $\begin{array}{l}\text { vezes } \\
\text { mês }\end{array}$ & $\begin{array}{c}1 \mathrm{a} 3 \\
\text { pors }\end{array}$ & $\begin{array}{l}\text { ezes } \\
\text { nana }\end{array}$ & & $\begin{array}{l}\text { dos } \\
\text { dias }\end{array}$ & $\begin{array}{l}\text { Não } \\
\text { realiza }\end{array}$ \\
\hline & $n$ & $\%$ & $\mathrm{n}$ & $\%$ & $\mathrm{n}$ & $\%$ & $\%$ \\
\hline
\end{tabular}

Ações individuais na USF

Atendimento à demanda espontânea

Consulta clínica individual à população cadastrada

Consulta clínica individual para grupos prioritários

Atendimento de urgência

Ações de educação em saúde

Atividades em grupo e comunitárias

Atividades de grupo com usuários na USF

Reunião com a comunidade

Visita domiciliar

Atividades de capacitação e gerenciais

Reunião de equipe

Atividades de capacitação

Reunião com a coordenação/ supervisão

Supervisão do trabalho dos auxiliares de enfermagem e ACS

Atividades de administração e gerência

$\begin{array}{rrrrrrrr}0 & 0,0 & 9 & 15,5 & 51 & 84,5 & 0 & 0,0 \\ 0 & 0,0 & 3 & 5,1 & 57 & 93,2 & 1 & 1,7 \\ 1 & 1,9 & 9 & 15,4 & 43 & 71,2 & 7 & 11,5 \\ 1 & 1,8 & 6 & 10,5 & 52 & 86,0 & 1 & 1,8 \\ 17 & 28,6 & 12 & 19,6 & 17 & 28,6 & 14 & 23,2\end{array}$

$\begin{array}{llllllll}24 & 39,0 & 20 & 32,2 & 0 & 0,0 & 17 & 28,8\end{array}$

$\begin{array}{llllllll}21 & 35,1 & 2 & 3,5 & 0 & 0,0 & 37 & 61,4\end{array}$

$\begin{array}{llllllll}17 & 28,3 & 40 & 65,0 & 0 & 0,0 & 4 & 6,7\end{array}$

$\begin{array}{llllllll}27 & 43,6 & 31 & 50,9 & 0 & 0,0 & 3 & 5,5\end{array}$

$\begin{array}{llllllll}25 & 40,4 & 8 & 14,0 & 1 & 1,8 & 27 & 43,9\end{array}$

$\begin{array}{lllllllll}45 & 74,1 & 9 & 15,5 & 0 & 0,0 & 6 & 10,3\end{array}$

$\begin{array}{llllllll}8 & 13,8 & 18 & 29,3 & 3 & 5,2 & 32 & 51,7\end{array}$

$\begin{array}{llllllll}4 & 7,1 & 6 & 10,7 & 2 & 3,6 & 48 & 78,6\end{array}$

\begin{tabular}{|c|c|c|c|c|c|c|c|c|}
\hline \multirow{3}{*}{ Atividades } & \multicolumn{8}{|c|}{ Vitória } \\
\hline & \multicolumn{2}{|c|}{$\begin{array}{l}1 \text { a } 2 \text { vezes } \\
\text { por mês }\end{array}$} & \multicolumn{2}{|c|}{$\begin{array}{c}1 \text { a } 3 \text { vezes } \\
\text { por semana }\end{array}$} & \multicolumn{2}{|c|}{$\begin{array}{l}\text { Todos } \\
\text { os dias }\end{array}$} & \multicolumn{2}{|c|}{$\begin{array}{l}\text { Não } \\
\text { realiza }\end{array}$} \\
\hline & $\mathrm{n}$ & $\%$ & $\mathrm{n}$ & $\%$ & $\mathrm{n}$ & $\%$ & & $\%$ \\
\hline \multicolumn{9}{|l|}{ Ações individuais na USF } \\
\hline Atendimento à demanda espontânea & 1 & 2,6 & 15 & 41,0 & & 56,4 & & $0 \quad 0,0$ \\
\hline Consulta clínica individual à população cadastrada & 0 & 0,0 & 3 & 7,7 & 34 & 92,3 & & $0 \quad 0,0$ \\
\hline Consulta clínica individual para grupos prioritários & 1 & 2,6 & 14 & 36,8 & 22 & 60,5 & & $0 \quad 0,0$ \\
\hline Atendimento de urgência & 1 & 2,6 & 17 & 44,7 & 16 & 42,1 & & 410,5 \\
\hline Ações de educação em saúde & 14 & 36,8 & 16 & 42,1 & 0 & 0,0 & & 821,1 \\
\hline \multicolumn{9}{|l|}{ Atividades em grupo e comunitárias } \\
\hline Atividades de grupo com usuários na USF & 12 & 33,3 & 19 & 51,3 & 0 & 0,0 & & 6 15,4 \\
\hline Reunião com a comunidade & 5 & 13,2 & 4 & 10,5 & 0 & 0,0 & & 876,3 \\
\hline Visita domiciliar & 8 & 20,5 & 28 & 74,4 & 1 & 2,6 & & 12,6 \\
\hline \multicolumn{9}{|l|}{ Atividades de capacitação e gerenciais } \\
\hline Reunião de equipe & 12 & 33,3 & 18 & 48,7 & 0 & 0,0 & & 717,9 \\
\hline Atividades de capacitação & 12 & 33,3 & 2 & 5,1 & 1 & 2,6 & & 259,0 \\
\hline Reunião com a coordenação/ supervisão & 22 & 59,5 & 3 & 8,1 & 0 & 0,0 & & 232,4 \\
\hline Supervisão do trabalho dos auxiliares de enfermagem e ACS & 4 & 10,8 & 2 & 5,4 & 3 & 8,1 & & 875,7 \\
\hline Atividades de administração e gerência & 5 & 13,2 & 2 & 5,3 & 1 & 2,6 & & 978,9 \\
\hline
\end{tabular}

Fonte: N upes/Daps/Ensp/Fiocruz. Pesquisa Saúde da Família, quatro estudos de caso, 2008. N ota: Aracaju: $n=55$ médicos; Belo H orizonte: $\mathrm{n}=72$ médicos; Florianópolis: $\mathrm{n}=61$ médicos; $\mathrm{V}$ itória: $\mathrm{n}=37$ médicos.

sociada com realização de atividades de grupo ( $p$ $=0,001$ ) e negativamente associada com realização de visita domiciliar $(p=0,000)$. O u seja, para médicos, ter curso em SF ou ser especialista em M FC relaciona-se com mais atividades de grupo, contudo, com visitação domiciliar menos frequente $(p=0,000)$. Para enfermeiros, não foi observada associação entre formação ou tempo de atua- ção e realização das atividades selecionadas. A análise das associações é apresentada na Tabela 4.

\section{Discussão}

As EqSF estabelecem ações prioritárias, mas estão concentradas em certos grupos populacio- 
Tabela 3. Frequência de atividades rotineiras informada por enfermeiros (\%) da Estratégia Saúde da Família, quatro grandes centros urbanos, 2008.

\begin{tabular}{|c|c|c|c|c|c|c|c|c|}
\hline \multirow{3}{*}{ Atividades } & \multicolumn{8}{|c|}{ Aracaju } \\
\hline & \multicolumn{2}{|c|}{$\begin{array}{l}1 \text { a } 2 \text { vezes } \\
\text { por mês }\end{array}$} & \multicolumn{2}{|c|}{$\begin{array}{l}1 \text { a } 3 \text { vezes } \\
\text { por semana }\end{array}$} & \multicolumn{2}{|c|}{$\begin{array}{l}\text { Todos } \\
\text { os dias }\end{array}$} & \multicolumn{2}{|c|}{$\begin{array}{l}\text { Não } \\
\text { realiza }\end{array}$} \\
\hline & $\mathrm{n}$ & $\%$ & $\mathrm{n}$ & $\%$ & $\mathrm{n}$ & $\%$ & $\mathrm{n}$ & $\%$ \\
\hline \multicolumn{9}{|l|}{ Ações individuais na USF } \\
\hline Atendimento à demanda espontânea & 1 & 1,5 & 2 & 3,0 & 64 & 95,5 & & 0,0 \\
\hline Consulta de enfermagem à população cadastrada & 1 & 1,5 & 4 & 6,0 & 62 & 92,5 & 0 & 0,0 \\
\hline Consulta de enfermagem para grupos prioritários & 4 & 6,0 & 22 & 32,8 & 39 & 58,2 & & 23,0 \\
\hline Atendimento de urgência & 11 & 16,4 & 90 & 13,4 & 22 & 32,8 & & 57,3 \\
\hline Ações de educação em saúde & 29 & 43,9 & 13 & 19,7 & 22 & 33,3 & 2 & 3,0 \\
\hline \multicolumn{9}{|l|}{ Atividades em grupo e comunitárias } \\
\hline Atividades de grupo com usuários na USF & 32 & 47,8 & 11 & 16,4 & 6 & 9,0 & & 326,9 \\
\hline Reunião com a comunidade & 37 & 55,2 & 2 & 3,0 & 2 & 3,0 & & 38,8 \\
\hline Visita domiciliar & 2 & 3,0 & 62 & 92,5 & 3 & 4,5 & 0 & 0,0 \\
\hline \multicolumn{9}{|l|}{ Atividades de capacitação e gerenciais } \\
\hline Reunião de equipe & 29 & 43,3 & 31 & 46,3 & 1 & 1,5 & & 59,0 \\
\hline Atividades de capacitação & 45 & 67,2 & 6 & 9,0 & 2 & 3,0 & & 420,9 \\
\hline Reunião com a coordenação/ supervisão & 42 & 62,1 & 4 & 6,1 & 1 & 1,5 & & 30,3 \\
\hline Supervisão do trabalho dos auxiliares de enfermagem e ACS & 51 & 7,6 & 17 & 25,8 & 44 & 65,2 & & 1,5 \\
\hline \multirow[t]{2}{*}{ Atividades de administração e gerência } & 80 & 11,9 & 80 & 11,9 & 6 & 9,0 & & 567,2 \\
\hline & \multicolumn{8}{|c|}{ Belo Horizonte } \\
\hline \multirow[t]{2}{*}{ Atividades } & \multicolumn{2}{|c|}{$\begin{array}{l}1 \text { a } 2 \text { vezes } \\
\text { por mês }\end{array}$} & \multicolumn{2}{|c|}{$\begin{array}{c}1 \text { a } 3 \text { vezes } \\
\text { por semana }\end{array}$} & \multicolumn{2}{|c|}{$\begin{array}{l}\text { Todos } \\
\text { os dias }\end{array}$} & \multicolumn{2}{|c|}{$\begin{array}{l}\text { Não } \\
\text { realiza }\end{array}$} \\
\hline & $\mathrm{n}$ & $\%$ & $\mathrm{n}$ & $\%$ & $\mathrm{n}$ & $\%$ & $\mathrm{n}$ & $\%$ \\
\hline \multicolumn{9}{|l|}{ Ações individuais na USF } \\
\hline Atendimento à demanda espontânea & 0 & 0,0 & 1 & 1,3 & 73 & 97,4 & 1 & 1,3 \\
\hline Consulta de enfermagem à população cadastrada & 2 & 2,6 & 22 & 29,9 & 50 & 66,2 & 1 & 1,3 \\
\hline Consulta de enfermagem para grupos prioritários & 12 & 15,4 & 38 & 50,0 & 17 & 23,1 & & 911,5 \\
\hline Atendimento de urgência & 13 & 16,7 & 18 & 24,4 & 31 & 41,0 & & 317,9 \\
\hline Ações de educação em saúde & 17 & 23,1 & 14 & 19,2 & 33 & 43,6 & & 14,1 \\
\hline \multicolumn{9}{|l|}{ Atividades em grupo e comunitárias } \\
\hline Atividades de grupo com usuários na USF & 28 & 37,7 & 34 & 45,5 & 1 & 1,3 & & 215,6 \\
\hline Reunião com a comunidade & 27 & 35,9 & 3 & 3,8 & 0 & 0,0 & & 500,3 \\
\hline Visita domiciliar & 15 & 20,5 & 56 & 74,4 & 0 & 0,0 & & 5,1 \\
\hline \multicolumn{9}{|l|}{ Atividades de capacitação e gerenciais } \\
\hline Reunião de equipe & 19 & 25,6 & 53 & 70,5 & 0 & 0,0 & & 3,8 \\
\hline Atividades de capacitação & 29 & 39,0 & 10 & 13,0 & 2 & 2,6 & & 445,5 \\
\hline Reunião com a coordenação/ supervisão & 38 & 51,3 & 8 & 10,3 & 1 & 1,3 & & 837,2 \\
\hline Supervisão do trabalho dos auxiliares de enfermagem e ACS & 38 & 5,1 & 10 & 12,8 & 61 & 80,8 & & 1,3 \\
\hline Atividades de administração e gerência & 12 & 15,6 & 15 & 19,5 & 20 & 27,3 & & 837,7 \\
\hline
\end{tabular}

nais e agravos, limitan do o alcancee a resolubilidade da ESF. A definição de número restrito de grupos prioritários dificulta o acesso e constituição da APS como porta de entrada preferencial ${ }^{12}$ e a baixa prioridade, conferida a determinados agravosinfecciosos de curso longo e elevada prevalência, incide sobre a qualidade do controle a estes problemas de saúde pública.
O binômio materno-infantil écentral no cuidado, e não é exclusivo a uma cesta seletiva de ações simplificadas e focalizadas, mas derivadas do cuidado à família, na perspectiva de uma APS abrangente ${ }^{15}$. A ções combinadas de planejamento familiar, prénatal, puerpério e saúde da criança podem garantir impactos significativos à mortalidade infantil ematerna ${ }^{16}$. A realização do con- 
Tabela 3. continuação

\begin{tabular}{|c|c|c|c|c|c|c|c|c|}
\hline \multirow{3}{*}{ Atividades } & \multicolumn{8}{|c|}{ Florianópolis } \\
\hline & \multicolumn{2}{|c|}{$\begin{array}{c}1 \text { a } 2 \text { vezes } \\
\text { por mês }\end{array}$} & \multicolumn{2}{|c|}{$\begin{array}{c}1 \text { a } 3 \text { vezes } \\
\text { por semana }\end{array}$} & \multicolumn{2}{|c|}{$\begin{array}{l}\text { Todos } \\
\text { os dias }\end{array}$} & \multicolumn{2}{|c|}{$\begin{array}{l}\text { Não } \\
\text { realiza }\end{array}$} \\
\hline & $\mathrm{n}$ & $\%$ & $\mathrm{n}$ & $\%$ & $\mathrm{n}$ & $\%$ & $\mathrm{n}$ & $\%$ \\
\hline \multicolumn{9}{|l|}{ Ações individuais na USF } \\
\hline Atendimento à demanda espontânea & 4 & 5,8 & 6 & 8,7 & 60 & 85,5 & 0 & 0,0 \\
\hline Consulta clínica individual à população cadastrada & 0 & 0,0 & 24 & 34,3 & 43 & 61,2 & 3 & 4,5 \\
\hline Consulta clínica individual para grupos prioritários & 5 & 7,7 & 36 & 50,8 & 24 & 33,8 & 5 & 7,7 \\
\hline Atendimento de urgência & 4 & 6,1 & 14 & 19,7 & 51 & 72,7 & 1 & 1,5 \\
\hline Ações de educação em saúde & 23 & 33,3 & 24 & 34,8 & 18 & 25,8 & 4 & 6,1 \\
\hline \multicolumn{9}{|l|}{ Atividades em grupo e comunitárias } \\
\hline Atividades de grupo com usuários na USF & 31 & 43,9 & 28 & 39,4 & 1 & 1,5 & 11 & 15,2 \\
\hline Reunião com a comunidade & 27 & 39,1 & 2 & 3,1 & 0 & 0,0 & 40 & 57,8 \\
\hline Visita domiciliar & 21 & 30,3 & 46 & 65,2 & 1 & 1,5 & 2 & 23,0 \\
\hline \multicolumn{9}{|l|}{ Atividades de capacitação e gerenciais } \\
\hline Reunião de equipe & 19 & 27,5 & 51 & 72,5 & 0 & 0,0 & 0 & \\
\hline Atividades de capacitação & 33 & 47,0 & 16 & 22,7 & 5 & 7,6 & 16 & 22,7 \\
\hline Reunião com a coordenação/ supervisão & 59 & 84,8 & 5 & 7,6 & 2 & 3,0 & 3 & 34,5 \\
\hline Supervisão do trabalho dos auxiliares de enfermagem e ACS & 5 & 7,5 & 11 & 16,4 & 52 & 74,6 & 1 & 1,5 \\
\hline \multirow[t]{2}{*}{ Atividades de administração e gerência } & 8 & 12,1 & 18 & 25,8 & 36 & 51,5 & 7 & 10,6 \\
\hline & \multicolumn{8}{|c|}{ Vitória } \\
\hline \multirow[t]{2}{*}{ Atividades } & \multicolumn{2}{|c|}{$\begin{array}{l}1 \text { a } 2 \text { vezes } \\
\text { por mês }\end{array}$} & \multicolumn{2}{|c|}{$\begin{array}{c}1 \text { a } 3 \text { vezes } \\
\text { por semana }\end{array}$} & \multicolumn{2}{|c|}{$\begin{array}{l}\text { Todos } \\
\text { os dias }\end{array}$} & \multicolumn{2}{|c|}{$\begin{array}{l}\text { Não } \\
\text { realiza }\end{array}$} \\
\hline & $\mathrm{n}$ & $\%$ & $\mathrm{n}$ & $\%$ & $\mathrm{n}$ & $\%$ & $\mathrm{n}$ & $\%$ \\
\hline \multicolumn{9}{|l|}{ Ações individuais na USF } \\
\hline Atendimento à demanda espontânea & 1 & 2,0 & 29 & 63,3 & 16 & 34,7 & 0 & 0,0 \\
\hline Consulta clínica individual à população cadastrada & 2 & 4,1 & 18 & 38.8 & 26 & 57,1 & 0 & 0,0 \\
\hline Consulta clínica individual para grupos prioritários & 4 & 8,5 & 31 & 68,1 & 10 & 21,3 & 1 & 2,1 \\
\hline Atendimento de urgência & 8 & 18,4 & 14 & 30,6 & 6 & 12,2 & & 38,8 \\
\hline Ações de educação em saúde & 18 & 38,8 & 23 & 51,0 & 5 & 10,2 & 0 & 0,0 \\
\hline \multicolumn{9}{|l|}{ Atividades em grupo e comunitárias } \\
\hline Atividades de grupo com usuários na USF & 16 & 34,7 & 24 & 53,1 & 3 & 6,1 & 3 & 6,1 \\
\hline Reunião com a comunidade & 10 & 20,8 & 8 & 18,7 & 0 & 0,0 & & 360,4 \\
\hline Visita domiciliar & 5 & 10,2 & 39 & 85,7 & 1 & 2,0 & & 2,0 \\
\hline \multicolumn{9}{|l|}{ Atividades de capacitação e gerenciais } \\
\hline Reunião de equipe & 15 & 32,7 & 31 & 67,3 & 0 & 0,0 & 0 & 0,0 \\
\hline Atividades de capacitação & 29 & 63,3 & 6 & 12,2 & 4 & 8,2 & & 16,3 \\
\hline Reunião com a coordenação/ supervisão & 27 & 58,3 & 11 & 25,0 & 0 & 0,0 & & 16,7 \\
\hline Supervisão do trabalho dos auxiliares de enfermagem e ACS & 4 & 8,3 & 12 & 27,1 & 29 & 62,5 & & 2,1 \\
\hline Atividades de administração e gerência & 7 & 16,7 & 14 & 31,2 & 16 & 35,4 & & 16,7 \\
\hline
\end{tabular}

Fonte: Nupes/Daps/Ensp/Fiocruz. Pesquisa Saúde da Família, quatro estudos de caso, 2008. N ota: Aracaju: $n=67$ enfermeiros; Belo H orizonte: $n=75$ enfermeiros; Florianópolis: $n=70$ enfermeiros; Vitória: $n=46$ enfermeiros.

trole do câncer uterino nas USF, com participação de médicos e enfermeiros, amplia o leque de proteção à mulher, além de possibilitar diagnóstico precoce, prevenindo-as demortes evitávei $s^{17}$.

Atenção aos idosos e às condições crônicas devem responder às mudanças nosológicas e garantir um envel hecimento mais saudável eativo. Um estudo que avaliou o uso de serviços básicos por idosos, portadores de condições crônicas, residentes em áreas com ESF, nas regiões Nordeste e Sul, indicou que esse modelo promove um maior acesso dos idosos ${ }^{18}$. N esse aspecto, os quatro centros urbanos avaliados apresentam certa homogeneidade na priorização da atenção ao idoso e alto envolvimento dos profissionais com condições crônicas não infecciosas. 
Tabela 4. Realização de atividades em grupo, reunião na comunidade e visita domiciliar segundo tempo de atuação e formação de médicos e enfermeiros, Estratégia Saúde da Família, quatro grandes centros urbanos, 2008.

\begin{tabular}{|c|c|c|c|c|c|c|c|c|c|c|}
\hline \multirow{4}{*}{ Variáveis } & \multicolumn{10}{|c|}{ Médicos } \\
\hline & \multicolumn{5}{|c|}{ Atividade em grupo } & \multicolumn{5}{|c|}{ Reunião com a comunidade } \\
\hline & \multicolumn{2}{|c|}{ Realiza } & \multicolumn{2}{|c|}{$\begin{array}{l}\text { Não } \\
\text { realiza }\end{array}$} & \multirow{2}{*}{$\begin{array}{l}\text { Valor } \\
\text { dep }\end{array}$} & \multicolumn{2}{|c|}{ Realiza } & \multicolumn{2}{|c|}{$\begin{array}{l}\text { Não } \\
\text { realiza }\end{array}$} & \multirow{2}{*}{$\begin{array}{l}\text { Valor } \\
\text { de } p\end{array}$} \\
\hline & $\mathrm{n}$ & $\%$ & $\mathrm{n}$ & $\%$ & & $\mathrm{n}$ & $\%$ & $\mathrm{n}$ & $\%$ & \\
\hline \multicolumn{11}{|l|}{ Tempo de atuação } \\
\hline Até 48 meses & 89 & 73,1 & 33 & 26,9 & \multirow{3}{*}{0,171} & 42 & 34,8 & 78 & 65,2 & \multirow{3}{*}{0,113} \\
\hline Mais de 48 meses & 67 & 66,4 & 34 & 33,6 & & 27 & 27,0 & 72 & 73,0 & \\
\hline Total & 156 & 70,1 & 67 & 29,9 & & 69 & 31,3 & 150 & 68,7 & \\
\hline \multicolumn{11}{|l|}{ Formação } \\
\hline \multicolumn{11}{|l|}{ Em Saúde da Família (SF) } \\
\hline Com curso especialização & 68 & 80,2 & 17 & 19,8 & \multirow{3}{*}{0,001} & 22 & 26,0 & 62 & 74,0 & \multirow{3}{*}{0,099} \\
\hline Sem curso especialização & 86 & 63,3 & 50 & 36,7 & & 46 & 34,1 & 88 & 65,9 & \\
\hline Total & 154 & 69,8 & 67 & 30,2 & & 68 & 31,0 & 150 & 69,0 & \\
\hline \multicolumn{11}{|c|}{ Em M edicina de Família e Comunidade (M FC) } \\
\hline Especialista & 43 & 82,7 & 9 & 17,3 & \multirow{3}{*}{0,001} & 15 & 28,9 & 37 & 71,1 & \multirow{3}{*}{0,52} \\
\hline Não é especialista & 113 & 66,3 & 58 & 33,7 & & 54 & 32,0 & 114 & 68,0 & \\
\hline \multirow[t]{5}{*}{ Total } & 156 & 70,1 & 67 & 9,9 & & 69 & 31,3 & 151 & 68,7 & \\
\hline & \multicolumn{10}{|c|}{ Enfermeiros } \\
\hline & \multicolumn{5}{|c|}{ Atividade em grupo } & \multicolumn{5}{|c|}{ Reunião com a comunidade } \\
\hline & \multicolumn{2}{|c|}{ Realiza } & \multicolumn{2}{|c|}{$\begin{array}{l}\text { Não } \\
\text { realiza }\end{array}$} & \multirow{2}{*}{$\begin{array}{l}\text { Valor } \\
\text { dep }\end{array}$} & \multicolumn{2}{|c|}{ Realiza } & \multicolumn{2}{|c|}{$\begin{array}{l}\text { Não } \\
\text { realiza }\end{array}$} & Valor \\
\hline & $\mathrm{n}$ & $\%$ & $\mathrm{n}$ & $\%$ & & $\mathrm{n}$ & $\%$ & $\mathrm{n}$ & $\%$ & \\
\hline Tempo de atuação & & & & & & & & & & \\
\hline Até 48 meses & 110 & 85,5 & 19 & 214,5 & & 55 & 41,8 & 76 & 58,2 & \\
\hline Mais de 48 meses & 99 & 80,8 & 24 & 19,2 & 0,228 & 60 & 50,3 & 59 & 49,7 & 0,079 \\
\hline Total & 209 & 83,2 & 43 & 16,8 & & 115 & 45,8 & 135 & 54,2 & \\
\hline Formação Em Saúde da Família & & & & & & & & & & \\
\hline Com curso especialização & 91 & 80,9 & 22 & 19,1 & & 54 & 48,0 & 58 & 52,0 & \\
\hline Sem curso especialização & 117 & 85,6 & 20 & 14,4 & & 60 & 44,4 & 75 & 55,6 & \\
\hline Total & 208 & 83,5 & 42 & 16,5 & 0,247 & 114 & 46,0 & 133 & 54,0 & 0,472 \\
\hline
\end{tabular}

Uma lacuna nas práticas prioritárias situa-se na faixa dos adolescentes, visto que médicos e enfermeiros relataram baixo envolvimento com esse grupo no seu cotidiano, o que pode estar relacionado, também, à baixa demanda espontânea deste grupo. Ferrari e Thomson ${ }^{19}$ e Ruzany et al..$^{20}$ apontam que 0 número de adolescentes que procuram as USF é reduzido e os incentivos institucionais para essa população não têm se revertido em novas e criativas práticas. Alguns aspectos que podem agravar tal situação é o horário/local de funcionamento das USF, incompatíveis com a escola e o trabalho, atrativos para a procura (atividades educativas, ações específicas, capacidade técnica dos profissionais), autopercepção da necessidade, dentre outras. Trata-se de grupo complexo, heterogêneo e vulnerável à DST/Aids, gravidez, drogas, violência, o que implicaria em iniciativas específicas ${ }^{21}$.

N ão obstante, atividades relacionadasà DST / Aids foram pouco referidas como prioritárias pelos profissionais, expondo uma situação preocupante, por conta da gravidade e elevada incidência nas quatro cidades22. Trata-se de ação que deve estar atrelada a outras (pré-natal, controle do câncer uterino, planejamento familiar, atenção ao adolescente), transversalmente ${ }^{23}$. Constata-se que, apesar da realização de ações prioritárias, as práticas assistenciais requerem maior integração entre profissionais e entre ações do 
Tabela 4. continuação

\begin{tabular}{|c|c|c|c|c|c|}
\hline \multirow{4}{*}{ Variáveis } & \multicolumn{5}{|c|}{ Médicos } \\
\hline & \multicolumn{5}{|c|}{ Visita domiciliar } \\
\hline & \multicolumn{2}{|c|}{ Realiza mais } & \multicolumn{2}{|c|}{ Realiza pouco } & \multirow{2}{*}{ Valor de $p$} \\
\hline & $\mathrm{n}$ & $\%$ & $\mathrm{n}$ & $\%$ & \\
\hline \multicolumn{6}{|l|}{ Tempo de atuação } \\
\hline Até 48 meses & 92 & 74,9 & 31 & 25,1 & \multirow{3}{*}{0,316} \\
\hline Mais de 48 meses & 71 & 70,6 & 30 & 29,4 & \\
\hline Total & 163 & 73,0 & 61 & 27,0 & \\
\hline \multicolumn{6}{|l|}{ Formação } \\
\hline \multicolumn{6}{|l|}{ Em Saúde da Família (SF) } \\
\hline Com curso especialização & 53 & 61,7 & 33 & 38,3 & \multirow{3}{*}{0,000} \\
\hline Sem curso especialização & 109 & 79,7 & 28 & 20,3 & \\
\hline Total & 162 & 72,7 & 61 & 27,3 & \\
\hline \multicolumn{6}{|c|}{ Em M edicina de Família e Comunidade (M FC) } \\
\hline Especialista & 30 & 57,6 & 22 & 42,4 & \multirow{3}{*}{0,000} \\
\hline Não é especialista & 134 & 77,6 & 39 & 22,4 & \\
\hline \multirow[t]{5}{*}{ Total } & 164 & 73,0 & 61 & 27,0 & \\
\hline & \multicolumn{5}{|c|}{ Enfermeiros } \\
\hline & \multicolumn{5}{|c|}{ Visita domiciliar } \\
\hline & \multicolumn{2}{|c|}{ Realiza mais } & \multicolumn{2}{|c|}{ Realiza pouco } & \multirow{2}{*}{ Valor de $p$} \\
\hline & $\mathrm{n}$ & $\%$ & $\mathrm{n}$ & $\%$ & \\
\hline \multicolumn{6}{|l|}{ Tempo de atuação } \\
\hline Até 48 meses & 105 & 80,5 & 26 & 19,5 & \\
\hline M ais de 48 meses & 99 & 80,9 & 23 & 19,1 & 0,917 \\
\hline Total & 204 & 80,7 & 49 & 19,3 & \\
\hline \multicolumn{6}{|c|}{ Formação Em Saúde da Família (SF) } \\
\hline Com curso especialização & 90 & 78,8 & 24 & 21,2 & \\
\hline Sem curso especializacão & 112 & 81,8 & 25 & 18,2 & \\
\hline Total & 202 & 80,5 & 49 & 19,5 & 0,394 \\
\hline
\end{tabular}

Fonte: Nota 1: $n=225$ médicos en $=258$ enfermeiros. Nota 2: Realiza mais - realiza visita domiciliar pelo menos 1 vez por semana. Realiza pouco - realiza visita domiciliar, no máximo, 1 ou 2 vezes ao mês, ou não realiza.

mesmo profissional para que questões como DST/Aids não se limitem a momentos pontuais, grupos específicos, protocolos verticais ou distribuição de insumos.

Em relação ao controle de dengue, a baixa priorização das ações, para a maior parte dos profissionais, torna-se preocupante, pois o agravo alçou grande magnitude, com ampliação de óbitos na maior parte do país. 0 caráter residual em Florianópolis pode está atrelado ao Índice de Infestação Predial que éconsiderado satisfatório e pelo fato de que até 2008 , Santa Catarina, continuava sem transmissão autóctone ${ }^{24}$. Combate à dengue pelas EqSF é defendido pelo Programa $\mathrm{N}$ acional de Controlede Dengue, embora a efici- ência das práticas desenvolvidas seja pouco conhecida, além das dificuldades, em cidades grandes e cidades turísticas ${ }^{25}$.

Atenção à tuberculose nas EqSF faz parte do Plano Nacional de Controle da Tuberculose que orienta profissionais e gestores às responsabilidades perante ações de cuidado ao agravo, inclusive em virtude da relação à infecção por HIV. Esse procedimento na APS deveser organizado a partir das dimensões enfoque familiar e orientação para a comunidade, para facilitar o acesso, aumentar a adesão ao tratamento, diminuir custos e mortalidade evitável26. Todavia, destaca-se o caráter residual dessa atividade no âmbito das EqSF. Apesar de ser comum aos médicos e enfer- 
meiros de Aracaju e enfermeiros de Vitória, necessita de maior envolvimento dos profissionais nas demais cidades, uma vez que somente metade define-a como prioridade.

Controledahanseníasetambém integra a área estratégica para operacional ização da APS no Brasil $^{9}$. O Programa Nacional de Controle da $H$ anseníase aponta a descentralização do controle para as EqSF que deve centrar esforços na cura de todos os casos que devem ser diagnosticados precocemente e na vigilância de contatos, especialmente para menores de 15 anos $^{27}$. 0 que provoca um alerta, pois ficou evidente nas cidades investigadas a insuficiência nas práticas assistenciais dirigidas a adolescentes.

Os tradicionais programas de saúde pública para tuberculose e hanseníase estavam descentralizados para as USF em Aracaju (baciloscopia e acompanhamento) e Belo Horizonte (acompanhamento) e em processo de descentralização em Florianópolis e Vitória, sendo que, todas as cidades possuem Centros de Referência que coordenam as ações na rede ${ }^{3}$. A descentralização implementada em Aracaju ajuda a compreender o maior envolvimento da equipe, uma vez que há maior adensamento de ações assistenciais na USF relacionado aos referidos agravos. Porém, a centralização do cuidado nos Centros de Referências (Florianópolis e Vitória) restringe a ação da ESF, fragmenta as ações prioritárias, fragilizando a coordenação pela APS, compromete o vínculo do portador de tuberculose ou hanseníase com a EqSF, pois aquele precisará ser cuidado em outro território.

Uma característica que reforça a mudança no cotidiano das práticas centra-se na forma como os profissionais respondem às ações programáticas da demanda organizada e ao mesmo tempo acolhem a demanda espontânea. EqSF que organizam a demanda, mas permitem que necessidades rotineiras e imprevisíveis encontrem respostas adequadas têm maiores chances de ser o serviço de primeiro contato e de uso continuado, porquanto, cumprem uma característica-força da APS "promover o primeiro acesso a cada nova necessidade" 28 . N esse estudo, constata-se que médicos e enfermeiros, ademais de organizar a demanda por ações prioritárias, permanecem atentos às demandas imprevistas, corroborando para processos de trabal ho centrados no usuário e serviços de procura regular de porta aberta ${ }^{15}$.

A consulta clínica individual, historicamente de responsabilidade médica, na ESF, passa a ser compartilhada com ações individuais dos enfermeiros, podendo ampliar e potencializar o cui- dado. Atividade rotineira ligada à consulta individual, por outro lado, pode significar um aprisionamento da enfermagem em atividades procedimento-centradas, reproduzindo-se o modelo quese busca superar, ou poderepresentar uma ampliação de suas atribuições com a valorização de seu núcleo de conhecimento, reestruturando a produção do cuidado. Trata-se de uma ação prevista pela PNAB, que incentiva e instrui essa atribuição mediante disposições legais da profissão e deliberações do gestor local ${ }^{9}$.

Entre atividades rotineiras, a presença de atividades de grupo com usuários na USF, ainda que respondam a uma programação institucional e programática, podem representar ganho qualitativo ao inserir elementos pedagógicos às ações clínicas tradicionais. Porém, a escassez de reuniões com a comunidade, ou seja, insuficiência deatividades mais amplas ( preventivas e promocionais) e debates acerca dos determinantes sociais da saúde, no âmbito do território, fragiliza a ESF, pois limita a responsabilidade sanitária e restringe as atividades rotineiras a ações clínico-ambulatoriais.

Atividades em grupo com usuários na USF devem ter a perspectiva de ampliação da clínica, possibilitando a introdução de orientações e atividades educativas com temas diversos, aumentando as discussões de promoção da saúdeeconstrução de novas abordagens em relação ao cuidado ${ }^{23}$. Transformar o equipamento assistencial em espaço pedagógico permite à USF tornar-se um lócus de encontros para além da doença, posto que "paralela à linha de produção do cuidado, há uma linha de produção pedagógica na estrutura organizacional do SU S"29.

A adesão demédicos eenfermeiros a essa prática pode implicar em reordenação da práxis, inclusive potencializando a aderência dos usuários ao serviço. As evidências apontam que, na APS, atividades de prevenção são mais impactantes quando relacionadas a questões mais "genéricas" (estilos de vida), ou seja, não limitadas a uma doença em particular ${ }^{28}$.

Reuniões com a comunidade seguem a mesma lógica, alargar o processo de trabalho dos médicos e enfermeiros, colocando-os frente a frente com problemas coletivos, com possibilidade de exercerem outras competências. Contudo, nos municípios pesquisados, a baixa frequência revela menor envolvimento desses trabaIhadores com essa ação, podendo comprometer a lógica de mudança de model o preconizado pela ESF. É comum, inclusive, focalizar a crítica na categoria médica, mas os achados nos quatros 
centros investigados constatam que mesmo enfermeiros têm reproduzido uma prática mais individual. Tais evidências fragilizam a APS na dimensão "orientação para a comunidade"12 e no trabalho intersetorial ${ }^{5}$.

Educação em saúde desvela-se como atividade inusitada, pois, ainda que, em algum momento, faça parte das práticas da maioria dos profissionais, parece ser compreendida apenas como uma ação específica, atrelada a um local, dia e grupo específico, posto que, os entrevistados não relacionam essa atividade como basilar à consulta rotineira, ou seja, enquanto um momento pedagógico e oportuno para identificar vulnerabilidades eincentivar ações preventivas ${ }^{15}$.

Visita domiciliar é uma atividade comum a todos, porém, ainda precisa de incorporação semanal na agenda dos médicos, porquanto pode fortalecer a APS na dimensão "orientação para a comunidade"12. A visita aos domicílios e outros espaços comunitários precisa ser qualificada, propositiva e direcionada a problemas específicos. Presença de tais práticas, em si, pode implicar em mudanças na forma de cuidar, principalmente, dos médicos tradicional mentevinculados ao consultório e às tecnologias duras, desde que abarquem, no processo terapêutico, tecnologias relacionai $s^{30}$. Além disso, permite identificação de risco evulnerabilidadedosindivíduos, famílias e setores do território, além de favorecer o vínculo entre equipee comunidade, aumentando a capilaridade da clínica e a construção de projetos terapêuticos mais precisos ${ }^{10}$.

0 trabalho multiprofissional einúmeras ações rotineiras exigem parcerias, inclusive, nas atividades de administração e gerência, nas reuniões de equipe ( planejamento eavaliação) e acompanhamento do trabalho técnico ${ }^{31}$.

Esperava-se, também, que um tempo maior de experiência profissional na ESF, impactasse na realização de mais atividades em grupo, reuniões na comunidade e visitas domiciliares, contudo, a análise estatística de associação entre variáveis apresentaalguns resultadosinusitadosque tencionam discursos largamente proferidos. Para o conjunto dos profissionais, não se observaram associações estatisticamente significativas entre o tempo de atuação de médicos eenfermeirosna ESF euma maior ou menor realização das atividades selecionadas.

Os resultados sobre qualificação profissional epráticas assistenciais trouxeram indíciosque precisarão de novas pesquisas para identificar problemas na qualidade da formação (orientação teórica, cenários de práticas e orientação pe- dagógica), uma vez que a especialização em SF para enfermeiro não esteve associada a um maior ou menor desempenho nas três atividadestestadas, contrariando a expectativa. Em relação aos médicos, essa associação foi paradoxal, pois ter curso em SF ou ser especialista em M FC significou realizar mais atividades de grupo, ao mesmo tempo em que esteve associado a realizar visitas domiciliares com menor frequência.

Parece haver problemas apontados para diversos vetores, exigindo uma retomada crítica de posição e/ou uma radical reformulação nos modelos de qualificação dos profissionais. Investigando os mesmos municípios, M endonça et al. ${ }^{4}$ consideram que existem avanços por meio da regularização dos vínculos de trabalho, adequação da remuneração e dispositivos para qualificação dos trabalhadores (tecnologias de informação e comunicação, integração de profissionais de diferentes pontos da rede, linhas de cuidado, USF como campo de aprendizagem, cursos de especialização etc.), mas ainda insuficientes para garantir a consolidação da ESF.

Não obstante, mudanças no processo de trabalho requerem mais que capacitações pontuais ou especializações ${ }^{15}$, haja vista a enorme oferta de cursos em todo país e o "baixo impacto desses mesmos programas de educação para o setor da saúde nos processos produtivos, isto é, na prática cotidiana de produção do cuidado" ${ }^{29}$. Há a necessidade de repensar a qualificação mais adequada para a ESF, com conteúdos que desenvolvam competências à APS, fornecendo ferramentas teóricas e técnicas necessárias ao cuidado de pessoas em diferentes fases da vida e com distintos problemas de saúde, tudo isso atrelado a uma política de gestão do trabalho e educação permanente em saúde.

\section{Considerações finais}

A análise realizada indica tendência a um balanço entre atendimentos às demandas programadas e à demanda espontânea, corroborando práticas centradas nas pessoas, sendo essa característica esperada numa APS que seja resolutiva e se proponha a ser reconhecida como serviço de procura regular. Distingue-se, assim, de outras modalidades que realizam ações programáticas concentradas em certos grupos populacionais, queexcluem al gumas pessoas e limitam seu acesso; de EqSF muito fechadas, que somente atendem à demanda organizada, limitam o acesso e perdem oportunidades de atendimento oportu- 
no e, por fim, de USF que somente atendem demanda espontânea, nesse caso, trata-se de um modelo tradicional de queixa-consulta, não devendo ser classificada como APS.

Ações a agravos infecciosos de curso longo não são prioridades no âmbito de todas as EqSF, comprometendo as ações de vigilância à saúde e as práticas integrais. Tal constatação, somada ao insuficiente envolvimento com atividade na comunidade tendem a limitar a produção do cuidado às práticas convencionais e comprometer a lógica de mudança de modelo. É necessário incentivar a atenção domiciliar para que seja uma prática semanal para todos os profissionais, principalmente médicos, como forma de aproximação com redes familiares e sociais, bem como ampliar o espectro das intervenções clínicas, compreendendo cada contato como momento oportuno para identificar grupos vulneráveis, superando a dicotomia prevenção-tratamento.

A consulta individual demédicos e enfermeiros parece ampliar e potencializar as práticas assistenciais, pois al gumas ações são realizadas por ambos. Apesar disso, pode significar um aprisionamento da enfermagem em atividades procedimento-centradas, reproduzindo-se o modelo que se busca superar, ou pode representar ampliação de suas atribuições com valorização de seu núcleo de conhecimento, favorecendo a assistência integral. Portanto, as orientações dos gestores devem coordenar a lógica assistencial, incentivando a criatividade e a autonomia das equipes, utilizando protocolos e normas como instrumentos flexíveis e apoiadores no processo de educação permanente para uma prática qualificada, pois a união dessas orientações pode conceber práticas assisten ciais mais resolutivas ${ }^{2,10}$.

$\mathrm{N}$ as cidades analisadas, contradições entre formação e práticas sugerem novas investigações, visto que mudanças no processo de trabalho requerem mais que capacitações pontuais. Evidencia-se que a qualificação profissional, por si, não produz melhores práticas assistenciais, reforçando a necessidade do papel indutor e ordenador do MS, articulado ao Ministério da Educação, em cooperação com instituições formadoras, conselhos de classe e municípios, para garantir que a formação esteja relacionada às necessidades sociais e à operacionalização do SUS.

Ressalta-se, porém, que a aferição da frequência das práticas não significa análise de sua qualidade ou ef etividade. Especificidades locais, de diversas ordens, poderiam explicar a situação apresentada. Entre as dificuldades encontradas para estabelecimento de padrões que possam orientar o processo de trabalho em busca de qualidade para as EqSF em seu conjunto, destaca-se o fato do modelo proposto ainda estar em construção, com grande diversidade de concepções, práticas, condições de estrutura e resultados entre municípios.

Os casos estudados têm experiências de implementação da ESF mais consolidadas do que outros grandes centros urbanos. Assim, problemas desvelados podem ser ainda de maior intensidade em inúmeros outros cenários, que se encontram com menor cobertura, dificuldade na fixação e qualificação de profissionais, restrição financeira, dentre outros, requerendo processos de monitoramento rotineiro.

Os resultados também inovam ao buscar associações entre características do perfil profissional e a realização de determinadas práticas assistenciais, posto que são escassas investigações com tais inter-relações. Deste modo, para além das inovações, 0 artigo agrega evidências a outros estudos, colaborando para o fortalecimento dos discursos e reflexão acerca das práticas assistenciais desenvolvidas, bem como, pode contribuir para repensar processos formadores em saúde.

No conjunto das informações sobre ações prioritárias e atividades rotineiras, profissionais inquiridos dão pistas dos caminhos que estão desenhando na micropolítica do trabal ho cotidiano. Ositinerários detrabal ho desenvolvidos por médi cos e enfermeiros servem de mote para consubstanciar os alicerces na implementação da ESF nos grandes centros urbanos, bem como, ajudam a identificar convergências e dissonâncias pertinentes à reelaboração de propostas e políticas para consolidação da APS, no Brasil. 


\section{Colaboradores}

AM Santos analisou os dados, redigiu e organizou 0 artigo. L Giovanella coordenou a pesquisa, participou da concepção erevisou o artigo. M H M Mendonça participou da pesquisa e revisou 0 artigo. CLT Andrade colaborou na metodologia e análise estatística. M IC M artins e M S Cunha colaboraram na pesquisa e redação preliminar.

\section{Referências}

1. Campos GWS. Reforma política e sanitária: a sustentabilidade do SUS em questão? Cien Saude Colet 2007; 12(2):301-306.

2. Assis M MA, N ascimento MAA, Franco TB, Jorge MSB. Produção do cuidado no programa Saúde da Família: olhares analisadores em diferentes cenários. Salvador: Edufba; 2010.

3. Giovanella G, Escorel S, M endonça M HM, coordenadores. Estudos de Caso sobre Implementação da Estratégia Saúde da Família em Quatro Grandes Centros U rbanos. Relatório Final. Rio de Janeiro: Fiocruz, Ensp, Daps, N upes; 2009.

4. M endonça MHM, M artins M IC, Giovanella L, Escorel S. Desafios para gestão do trabalho a partir de experiências exitosas de expansão da Estratégia de Saúde da Família. Cien Saude Colet 2010; 15(5):23552365.

5. Giovanella $L$, M endonça $M H H$, Escorel $S$, Almeida PF, Fausto MCR, Andrade CLT, M artins MIC, Senna MCM, Sisson MC. Potencialidades e obstáculos para a consolidação da Estratégia Saúde da Família em grandes centros urbanos. Saude em debate 2010; 34(85):248-264.

6. Giovanella L, M endonça M HM, Almeida PF, Escorel S, Senna MCM, Fausto MCR, Delgado MM, Andrade CLT, Cunha MS, Martins MIC, Teixeira CP. Saúde da família: limites e possibilidades para uma abordagem integral de atenção primária à saúde no Brasil. Cien Saude Colet 2009; 14(3):783-794.

7. Macinko J, Almeida C, Oliveira, ES. Avaliação das características organizacionais dos serviços de atenção básica em Petrópolis: teste de uma metodologia. Saude D ebate 2003; 27(65):243-256.

8. Araújo MBS, Rocha PM. Saúde da família: mudando práticas? Estudo de caso no município de $\mathrm{Natal}$ (RN). Cien Saude Colet 2009; 14(Supl.):1439-1452.

9. Brasil. Portaria n. 648/GM , de 28 de março de 2006. Política Nacional de Atenção Básica. Diário Oficial da União 2006; 29 mar.

10. Campos GWS, Gutiérrez AC, Guerrero AVP, Cunha GT. Reflexões sobre atenção básica e a estratégia de Saúde da Família. In: Campos GWS, Guerrero AVP, organizadores. M anual de práticas de atenção básica: saúde ampliada e compartilhada. São Paulo: Hucitec; 2008. p. 132-153.

11. Macinko J, Starfield B, Shi L. The contribution of primary care systems to health outcomes within Organization for Economic Cooperation and Development (OECD) countries, 1970-1998. Health Serv Res 2003; 38(3):831-865.

12. Starfield B. Atenção primária: equilíbrio entre necessidades de saúde, serviços e tecnologia. Brasília: Unesco, M S; 2002

13. Conill EM, Fausto MCR, Giovanella L. Contribuições da análise comparada para um marco abrangente na avaliação de sistemas orientados pela atenção primária na América Latina. Rev. Bras. Saude M atern. Infant. 2010; 10(Supl.1):15-27.

14. Delnoij D, Van Merode G, Paulus A, Groenewegen $P$. Does general practitioner gatekeeping curb health care expenditure? J Health Serv Res Policy 2000; $5(1): 22-26$. 
15. World Health Organization (WHO). Primary Health Care. Now more than ever. The World Health Report 2008. Geneva: WHO; 2008.

16. Rohde J, Cousens S, Chopra M, Tangcharoensathien V, Black R, Bhutta ZA, Lawn JE. 30 years after Alma-Ata: has primary health care worked in countries? Lancet 2008; 372(9642):950-961.

17. Albuquerque KM, Frias PG, Andrade CLT, Aquino $E M L$, M enezes G, Szwarcwald CL. Cobertura do teste de Papanicolau e fatores associados a nãorealização: um olhar sobre o Programa de Prevenção do Câncer do Colo do Útero em Pernambuco, Brasil. Cad Saude Publica 2009; 25(Supl. 2):301-309.

18. Rodrigues MAP, Facchini LA, Piccini RX, Tomasi $E$, Thumé E, Silveira DS, Siqueira FV, Paniz VM V. Uso de serviço básico de saúde por idosos portadores de condições crônicas, Brasil. Rev Saude Publica 2009; 43(4):604-612.

19. Ferrari RAP, Thomson Z. Atenção à saúde dos adolescentes: percepção dos médicos e enfermeiros das equipes da saúde da família. Cad Saude Publica 2006; 22(11):2491-2495.

20. Ruzany MH, Andrade CLT, Esteves M AP, Pina M F, Szwarcwald CL. Avaliação das condições de atendimento do Programa de Saúde do Adolescente no município do Rio de Janeiro. Cad Saude Publica 2002; 18(3):639-649.

21. Brasil. M inistério da Saúde (MS). Área de saúde do adolescente e do jovem. Saúde integral de adolescentes e jovens: orientações para a organização de serviços de saúde. Brasília: M S; 2005.

22. Brasil. M inistério da Saúde (MS). Boletim Epidemiológico Aids/DST. Ano VI - n.1. Brasília: M S; 2010.

23. Ferraz DAS, Nemes MIB. Avaliação de implantação de atividades de prevenção das DST/AIDS na atenção básica: um estudo de caso na Região Metropolitana de São Paulo, Brasil. Cad Saude Publica 2009; 25(Supl. 2):240-250.

24. Santa Catarina. Situação da dengue no Brasil e Santa Catarina - 2008. Vigilância Epidemiológica Santa Catarina, 2008. [página na Internet]. [acessado 2011 mar. 25]. Disponível em: http://www.dive.sc.gov.br/ conteudos/zoonoses/Vetores/A_Dengue_no_ Brasil_e_Santa_Catarina_2008.pdf
25. Wermelinger ED, Cohen SC, Thaumaturgo C, Silva AA, Ramos FAF, Souza M B. Avaliação do acesso aos criadouros do Aedes Aegypti por agentes de saúde do Programa Saúde da Família no município do Rio de Janeiro. Rev Baiana Saude Publica 2008; 32(2):151-158.

26. Oliveira SAC, Ruffino Neto A, Villa TCS, Vendramini SHF, Andrade RLP, Scatena LM. Serviços de saúde no controle de tuberculose: enfoque na família e orientação para a comunidade. Rev. Latinoam Enfermagem 2009; 17(3):1-7.

27. Brasil. Ministério da Saúde (MS). Vigilância em Saúde: situação epidemiológica da hanseníase no Brasil. Brasília: SVS, MS; 2008.

28. Starfield B, Shi L, M acinko J. Contribution of Primary Care to $\mathrm{H}$ ealth Systems and $\mathrm{H}$ ealth. M ilbank Q 2005; 83(3):457-502.

29. Franco TB. Produção do cuidado e produção pedagógica: integração de cenários do sistema de saúde no Brasil. Interface Comun Saude Educ 2007; $11(23): 427-438$.

30. Gariglio MT, Radicchi ALA. O modo de inserção do médico no processo produtivo em saúde: o caso das unidades básicas de Belo Horizonte. Cien Saude Colet 2008; 13(1):153-163.

31. Silva IZQJ, Trad LAB. 0 trabalho em equipe no PSF: investigando a articulação técnica e a interação entre os profissionais. Interface Comun Saude Educ 2004-05; 9(16):25-38.

Artigo apresentado em 13/04/2011

Aprovado em 08/06/2011

Versão final apresentada em 09/07/2011 